\title{
Barriers and Facilitators to Informed Decision- Making About Prostate Cancer Screening Among Black Men
}

\author{
Nicholas Shungu, MD, MPH, and Katberine R. Sterba, PhD
}

Background: Black men are disproportionately impacted by prostate cancer (PrCa). Current guidelines recommend that all men make informed decisions about whether to be screened for PrCa. Little is known about the barriers and facilitators of informed decision-making (IDM) about PrCa screening in Black men.

Methods: We conducted focus groups with a convenience sample of Black men aged 55 to 69 years from a primary care practice $(n=21)$. Template analysis was used to evaluate themes related to barriers and facilitators of IDM about PrCa screening.

Results: IDM was impacted by external factors, intrinsic factors, and personal beliefs about PrCa screening. Family, friends, and clinicians played a paramount role in shaping attitudes about PrCa screening.

Distrust of the medical community impaired IDM, and lack of clinician communication about PrCa screening further engendered mistrust. Participants felt they lacked adequate knowledge to make an informed decision about PrCa screening. Identified areas to promote IDM included education on racial disparities, education that screening is a personal choice, and differentiating PrCa screening from colon cancer screening.

Conclusions: Our results indicate that Black men may lack the prerequisite information to make informed decisions about PrCa screening, which is notable in light of known PrCa racial disparities. Clinicians can play an important role in facilitating IDM through fostering discussions about the benefits and risks of PrCa screening and educating Black men about racial disparities. ( $\mathrm{J}$ Am Board Fam Med 2021;34:925-936.)

Keywords: Cancer Screening, Decision Making, Focus Groups, Health Care Disparities, Primary Health Care, Prostate Cancer

\section{Introduction}

Prostate cancer $(\mathrm{PrCa})$ is the second-leading cause of cancer mortality among American men. ${ }^{1}$ Black men have a PrCa incidence rate that is 1.8 times as high and a mortality rate 2.2 times as high as White men. ${ }^{1}$ The Healthy People 2030 objectives include

This article was externally peer reviewed.

Submitted 5 April 2021; revised 10 June 2021; accepted 11 June 2021.

From the Department of Family Medicine, Medical University of South Carolina, Charleston, SC (NS); Department of Public Health Sciences and Hollings Cancer Center, Medical University of South Carolina, Charleston, SC (KRS).

Funding: The project described was supported by the South Carolina Clinical and Translational Research (SCTR) Institute, with an academic home at the Medical University of South Carolina, through NIH Grant Numbers UL1RR029882 and UL1 TR000062. The content is solely the responsibility of the authors and does not necessarily represent the official views of the National Center For Research Resources or the National Institutes of Health. reducing $\mathrm{PrCa}$ mortality by $10 \%$, with a focus on reducing disparate mortality outcomes for Black men. ${ }^{2}$ The optimal approach to PrCa screening in Black men remains controversial due primarily to the underrepresentation of this population in the studies that inform our understanding of $\mathrm{PrCa}$ screening. ${ }^{3,4}$ Prostate-specific antigen (PSA)-based screening in White men confers a slight mortality benefit but is associated with significant harms from overdiagnosis and side effects of cancer treatment. ${ }^{3}$ The 2018 United States Preventive Services Task Force (USPSTF) recommendations advise informed decision-making (IDM) conversations about the

Conflict of interest: There are no conflicts of interest or competing interests to report.

Corresponding author: Nicholas Shungu, MD, MPH, 5 Charleston Center Dr. Suite 263, MSC 192, Charleston SC, 29425, Telephone: 843-876-2926 (E-mail: shungu@musc. edu). 
benefits and risks of PSA screening for all men starting 55 to 69 years. ${ }^{5}$ No separate recommendations are made for Black men; however, the USPSTF encourages clinicians to inform Black men of their increased risk of developing and dying from PrCa. It is currently unclear whether the lack of universal screening recommendations for Black men contributes to disparate outcomes in PrCa mortality or to what extent Black men are harmed by PSA screening.

Despite known PrCa outcome disparities, prior studies demonstrate that Black men are less likely to receive PSA screening than White men. In 2018, the Centers for Disease Control and Prevention (CDC) reported that $40.4 \%$ of non-Hispanic White men aged 55 to 69 received PSA screening compared with $37.0 \%$ of non-Hispanic Black men. ${ }^{6}$ Racial disparities in $\mathrm{PrCa}$ screening are incompletely understood, but involve factors such as access to knowledge and health care, inadequate health care provider communication, and cultural beliefs. ${ }^{7-13}$ Given the disparate PrCa outcomes among Black men and the lack of universal screening guidelines, educating Black men to engage in informed decisions about PrCa screening is paramount. Previous qualitative work primarily focused on understanding the barriers that prevent Black men from undergoing PrCa screening. Barriers to PrCa screening in Black men include inadequate knowledge, access to care, cost, fear of cancer diagnosis, distrust of the medical community, aversion to prostate examination, and low perceived risk of PrCa. ${ }^{10-14}$ Few studies have acknowledged the uncertainties in PrCa screening among Black men, and the importance of IDM, given the potential benefits and harms of PrCa screening. However, several recent studies have started to fill that void. ${ }^{15-18}$ These studies were notably lacking in applying a theoretical framework to their investigations and took place before the USPSTF guidelines recommending IDM.

To help fill a gap in the literature, the current study used qualitative methods to explore how Black men feel about the possible benefits and harms of PrCa screening in light of the 2018 USPSTF recommendations. This study applied a theory-based framework to this question, being informed by the US Community Preventive Services Taskforce IDM Framework ${ }^{19}$ and with direct application of Prochaska's concept of decisional balance. ${ }^{20}$ This study aimed to characterize the factors impacting IDM among Black men regarding PrCa screening in the context of significant racial $\mathrm{PrCa}$ disparities.

\section{Methods}

The Consolidated Criteria for Reporting Qualitative Research (COREQ) checklist guided methods and results reporting. ${ }^{21}$ Study procedures were approved by the Medical University of South Carolina institutional review board. We recruited a convenience sample of self-identified Black men aged 55 to 69 who were approached face-to-face during office visits to an academic primary care clinic. Men with a history of $\operatorname{PrCa}$, men undergoing treatment for any cancer, men with a terminal illness, or men unable to give informed consent were excluded.

Data were collected through focus groups conducted between August 2019 and November 2019 by 2 investigators (NS, KRS) trained in qualitative research methods. One investigator was a Black male physician who practiced at the recruitment site, and the second was a public health researcher. The primary moderator had previously interacted in the health care setting with a minority of the participants. Data were collected in a private conference room at the clinic. A structured interview guide, derived from Krueger's focus group question guide and grounded in the US Community Preventive Services Taskforce IDM Framework, as well as Prochaska's concept of decisional balance, was used to facilitate discussion. ${ }^{19,20,22}$ The focus group interview guide was developed by the study team to address the potential risks and benefits of PrCa screening as detailed by the USPSTF, ${ }^{5}$ and to identify barriers and facilitators of making an informed decision. The study met standards for waiver of written informed consent. Participants received a verbal introduction before focus group participation regarding study purpose and potential benefits and harms. Initial questions focused on knowledge, attitudes, and experiences with $\mathrm{PrCa}$ screening. The questions were followed by a brief PowerPoint education session provided by the moderator about PrCa screening. The presentation was created by the moderator for the focus groups and included information about the 2018 USPSTF $\mathrm{PrCa}$ screening recommendations and American Cancer Society data on PrCa disparities. ${ }^{5,23}$ It also included potential limitations of the current 
guidelines as applied to Black men based on the lack of research in this area. The final focus group questions focused on perceived risks and benefits of PrCa screening based on the USPSTF guidelines. Decisional balance was assessed by asking the participants what they would recommend to a loved one about PrCa screening after discussing risks and benefits. The focus groups lasted approximately 90 minutes and were audio-recorded with extensive field notes taken. The study team evaluated progress regularly, and focus groups were conducted until data saturation was achieved. ${ }^{24}$ Participants completed a brief survey at the end of the focus group to assess sociodemographic factors and $\mathrm{PrCa}$ screening behaviors. The survey questions were derived from a previously published survey. ${ }^{25}$

\section{Data Analysis}

The audio-recorded interviews were transcribed and verified, and analysis was conducted using NVivo software. ${ }^{26}$ We used a template analysis technique ${ }^{27}$ with an initial codebook developed from theory and the literature, allowing additional codes to emerge directly from the data. The initial codebook was guided by the US Community Preventive Services Taskforce IDM Framework, ${ }^{19}$ which includes domains of: (1) understands the test, the condition, personal risks, uncertainties, (2) considers preferences, (3) participates in decision at a personally desirable level, (4) and makes a decision consistent with values (11 codes). Our review of the literature on $\mathrm{PrCa}$ screening decision making in Black men resulted in 2 additional codes not included within the IDM framework. ${ }^{28,29}$ Two investigators (NS, KRS) independently read and coded each interview, and differences were resolved through iterative discussion until a final agreement was reached. The codebook evolved throughout this process with the refinement of definitions for multiple codes and the addition and deletion of several codes (Appendix 1). The coders also noted whether the factors impacting IDM operated as barriers or facilitators of IDM.

\section{Results}

\section{Participant Characteristics}

A total of 21 men participated in 5 focus groups, with each focus group involving between 3 and 7 men. The median age of participants was 61 years (Table 1). A slight majority of participants had an
Table 1. Focus Group Participant Characteristics

\begin{tabular}{ll} 
(N = 21) & \\
\hline Characteristic & $\%$ \\
\hline Age, median, in years (range) & 61 (55 to 69) \\
Highest level of education & \\
Did not complete high school & 14.3 \\
High School/GED & 38.1 \\
Junior college/community college & 28.6 \\
Bachelor's Degree & 14.3 \\
No response & 4.8 \\
Partner status & \\
Married/Partnered & 47.6 \\
Divorced/Separated & 14.3 \\
Widowed & 4.8 \\
Single & 28.6 \\
No response & 4.8 \\
Knows family member/friend who has been & \\
diagnosed with prostate cancer & \\
Yes & \\
No & 61.9 \\
Has talked with a doctor about prostate cancer & \\
screening & 38.1 \\
Yes & \\
No & \\
Has been screened with a PSA blood test & \\
Yes & \\
No & 47.6 \\
\hline & 52.4 \\
\hline
\end{tabular}

GED, general education diploma; PSA, prostate-specific antigen.

education level of high school diploma or less. Over half were currently not married or partnered. Most of the participants knew a close family member or friend diagnosed with $\mathrm{PrCa}$, and most of the participants had previously spoken with a doctor about PrCa screening. Slightly over half of the participants had never received PSA screening.

Analysis resulted in 13 unique themes highlighting external factors $(n=2)$, intrinsic factors $(n=3)$ and beliefs $(\mathrm{n}=5)$ impacting IDM. Results also identified target areas to promote IDM $(n=3)$. Results below are organized to summarize these themes with definitions and illustrative quotes provided in Tables 2, 3, and 4 .

\section{External Factors Impacting IDM}

\section{Interpersonal Influences}

A universal theme throughout the focus groups was the role of key referent individuals (friends, family, churches) on men's understanding of both overall health and PrCa risk. These interpersonal 
Table 2. External and Intrinsic Factors Impacting Informed Decision-Making

\begin{tabular}{|c|c|c|}
\hline Theme & Definition & Quote \\
\hline \multicolumn{3}{|l|}{ External factors } \\
\hline Interpersonal influences & $\begin{array}{l}\text { Impact of important referent individuals on an } \\
\text { individual's opinions or beliefs about his } \\
\text { health. Includes both direct communication } \\
\text { and hearing stories of what has happened to } \\
\text { friends/family }\end{array}$ & $\begin{array}{l}\text { "Well, you know, I think... I think I'd go } \\
\text { through it (prostate cancer screening), only } \\
\text { for the knowin' so many people that's went } \\
\text { through it, and talking to them." (FG2) } \\
\text { "I think my father died from prostate cancer if } \\
\text { I'm not mistaken...And um, I've got a good } \\
\text { friend of mine, um, he say now any time after } \\
55 \text { its almost, like, imperative that you get } \\
\text { screened for prostate." (FG1) }\end{array}$ \\
\hline Clinician communication & $\begin{array}{l}\text { Impact of clinician on a man's behavior or } \\
\text { understanding. }\end{array}$ & $\begin{array}{l}\text { “We will accept that whatever our doctor tell } \\
\text { us,...and if they don't say anything, we just say } \\
\text { well that's cool. Everything alright. We just } \\
\text { will accept what our doctor says." (FG5) } \\
\text { "Well, I mean, pretty much mine just } \\
\text { recommended havin' the test." (FG2) }\end{array}$ \\
\hline \multicolumn{3}{|l|}{ Intrinsic factors } \\
\hline Pride* & $\begin{array}{l}\text { A feeling of manhood encompassing the } \\
\text { importance of strength, virility, and not } \\
\text { wanting to burden others }\end{array}$ & $\begin{array}{l}\text { "[Erectile dysfunction as a side effect of prostate } \\
\text { cancer treatment] would be devastating to } \\
\text { me. I got a wife at home, you know } \\
\text { (laughter). And if that were to happen to me, } \\
\text { shit, I mean, I don't know. You know, you } \\
\text { think about yourself less than a man." (FG1) } \\
\text { "They don't wanna see you in no pampers, you } \\
\text { know? That turns off everything!" (FG2) }\end{array}$ \\
\hline Care avoidance* & $\begin{array}{l}\text { Failure to care for oneself or seek medical care } \\
\text { even if one has the agency to do so }\end{array}$ & $\begin{array}{l}\text { "Some of these people just not used... they get } \\
\text { raised up in families that never go to doctors. } \\
\text { And I'm being serious. I grew up with plenty } \\
\text { of people that didn't go to doctors." (FG3) } \\
\text { "I came from a culture of men who didn't go to } \\
\text { doctors. My wife talk to me about it, but I go } \\
\text { to the doctor way more than most men I } \\
\text { know." (FG4) }\end{array}$ \\
\hline Motivated by racial disparities* & $\begin{array}{l}\text { Black men are motivated to seek additional } \\
\text { health information or to change health } \\
\text { behaviors due to their knowledge of health } \\
\text { disparities }\end{array}$ & $\begin{array}{l}\text { "I mean with the [knowledge that prostate } \\
\text { cancer disproportionately impacts Black men] } \\
\text { they probably would come get screened. You } \\
\text { know. They would deal with that risk." (FG2) } \\
\text { "It's sad that... the Black numbers [of } \\
\text { participants in research studies informing } \\
\text { prostate cancer screening knowledge] are that } \\
\text { low that y'all can't even really give us the } \\
\text { information that we really need." (FG3) }\end{array}$ \\
\hline
\end{tabular}

FG, focus group.

*Indicates code that was added during the iterative codebook review process

influences generally impacted participants in 3 ways: (1) direct advice to seek care or take care of oneself, (2) motivation to ask questions about $\mathrm{PrCa}$ risk after witnessing a close referent experience cancer, and (3) motivation to engage in PrCa screening stemming from witnessing a close referent experience $\operatorname{PrCa}$ (Table 2).

Men most commonly became aware of $\mathrm{PrCa}$ through experiencing a family member or friend who was diagnosed. Knowing someone who survived $\mathrm{PrCa}$ or who died from PrCa was an important motivator to get screened for PrCa. When men engaged in conversations with friends or family about $\mathrm{PrCa}$, the message they received was that they should be screened, without mention of potential harms.

When men reflected on the important factors regarding making an informed decision about $\mathrm{PrCa}$ screening, the role of their partners was paramount. Wives or partners were noted to encourage men to seek care in general, and specifically about PrCa screening. Some men expressed an understanding that weighing the potential downstream risks of PrCa treatment, such as erectile dysfunction with 
Table 3. Beliefs Impacting Informed Decision-Making

\begin{tabular}{|c|c|c|}
\hline Theme & Definition & Quote \\
\hline $\begin{array}{l}\text { Inadequate care from medical } \\
\text { community }\end{array}$ & $\begin{array}{l}\text { Men believe that the care provided to them is } \\
\text { insufficient or substandard, or men believe } \\
\text { that the information provided to them by the } \\
\text { medical community is incorrect or not } \\
\text { applicable to their personal situation }\end{array}$ & $\begin{array}{l}\text { "So yeah, your burden is basically to be able to } \\
\text { get more doctors out there talking to their } \\
\text { older Black male patients about what their } \\
\text { options are and delivering the information } \\
\text { they need so that they can make a } \\
\text { choice. . And I think that, in turn, would } \\
\text { bring down the death pattern from the mere } \\
\text { fact that you offered intelligent Black men, } \\
\text { which most of us are, damn it, a choice in } \\
\text { choosing what they do for their health." } \\
\text { (FG4) } \\
\text { "And um mostly a lot of Afro-American people } \\
\text { are thinking that when you go to the doctor } \\
\text { they are thinking about sometimes they } \\
\text { experiment on you. You know, from back in } \\
\text { the days..so they kinda cautious about that." } \\
\text { (FG1) }\end{array}$ \\
\hline Perceived barriers & $\begin{array}{l}\text { A man's feelings on the obstacles to completing } \\
\text { prostate cancer screening }\end{array}$ & $\begin{array}{l}\text { "I can say from being like an athlete or } \\
\text { whatever, you know, to me, you know, I'm } \\
\text { raised... don't nothin' go up there [rectum], } \\
\text { everything comes out. You know what I'm } \\
\text { saying? That's. . that's another kinda stigma } \\
\text { that plays in the mind." (FG4) } \\
\text { "For a lot of us, especially Black men, a lot of us } \\
\text { don't have health insurance or the money to } \\
\text { go to the doctors." (FG4) }\end{array}$ \\
\hline Perceived risk & $\begin{array}{l}\text { A man's perception of his susceptibility for } \\
\text { developing prostate cancer or developing } \\
\text { complications related to PSA testing. Also } \\
\text { includes a man's perception that something } \\
\text { is physically wrong. }\end{array}$ & $\begin{array}{l}\text { "Maybe down the road or if I see these } \\
\text { symptoms [frequent urination, getting up at } \\
\text { night to urinate] flaring up or happening, I'll } \\
\text { be more inclined to go get screened, cause } \\
\text { now I know that there is something going on, } \\
\text { you know." (FG4) } \\
\text { "Actually my brother, my brother, he had } \\
\text { [prostate cancer] he was in the service. He } \\
\text { went to the VA and they got, you know, he } \\
\text { got it taken care of. That's why I was } \\
\text { wondering that. . my brother is younger than } \\
\text { me, you know. He is } 60 \text {. You know, he is } \\
\text { younger than me and we may need to attempt } \\
\text { the things he's been telling me." (FG1) }\end{array}$ \\
\hline Perceived severity & $\begin{array}{l}\text { A man's feelings on the seriousness of } \\
\text { contracting prostate cancer }\end{array}$ & $\begin{array}{l}\text { "[Cancer will] take you out. It will take you out. } \\
\text { No doubt about it." (FG4) }\end{array}$ \\
\hline Perceived benefits & $\begin{array}{l}\text { A man's perception of the positive outcomes } \\
\text { derived from completing prostate cancer } \\
\text { screening }\end{array}$ & $\begin{array}{l}\text { "I've also heard that prostate cancer, if caught } \\
\text { early, detected early, it's one of the more } \\
\text { curable cancers, so that's something that you } \\
\text { might want to know so you can have that } \\
\text { knowledge to save your life. . I want to be } \\
\text { here for other people, my grandchildren and } \\
\text { my children, so at this point in my life I'm } \\
\text { trying to help other people. . and I think I } \\
\text { need to be here to do that." (FG4) }\end{array}$ \\
\hline
\end{tabular}

FG, focus group.

the potential benefits of survival, impacted their partner as well.

\section{Clinician Communication}

Communication with a clinician played an important role in health behavior change and understanding. Clinicians were described as trusted sources of information, and men who had an established relationship with a clinician felt that they would do whatever their clinician recommended regarding PrCa screening (Table 2). Some clinicians were noted to serve as key facilitators to making informed decisions by providing patients with information about the benefits and risks of screening. Conversely, participants also explained that clinicians sometimes recommended $\mathrm{PrCa}$ screening 
Table 4. Identified Target Areas for Facilitation of Informed Decision-Making

\begin{tabular}{|c|c|c|}
\hline Theme & Definition & Quote \\
\hline Lack of knowledge & $\begin{array}{l}\text { A man not possessing sufficient information } \\
\text { about prostate cancer screening to make an } \\
\text { informed decision. }\end{array}$ & $\begin{array}{l}\text { "Can't make an informed decision if you are not } \\
\text { informed. That's the bottom line." (FG4) } \\
\text { "And I've been to a bunch of doctors over the } \\
\text { years, well, especially over the past } 10 \text { years. } \\
\text { You know, and, not once has anyone ever } \\
\text { brought up prostate health or screening." } \\
\text { (FG4) }\end{array}$ \\
\hline $\begin{array}{l}\text { Key take-aways from education } \\
\text { session* }\end{array}$ & $\begin{array}{l}\text { The concepts that men felt were most } \\
\text { important or surprising after observing a } \\
\text { short presentation on prostate cancer } \\
\text { screening in Black men }\end{array}$ & $\begin{array}{l}\text { "I didn't know prostate is this deep! I though we } \\
\text { was gonna talk about the screening and the } \\
\text { enlargement and that, but you talk about } \\
\text { erection and leakin' and diaper } \\
\text { and. . perspective [of] loved ones." (FG3) } \\
\text { "You can live and be unhappy [due to erectile } \\
\text { dysfunction from treatment], or you can } \\
\text { choose [not to be screened for prostate } \\
\text { cancer]. Just a choice you have to make. With } \\
\text { what counts most to you." (FG2) }\end{array}$ \\
\hline Areas of confusion* & $\begin{array}{l}\text { Misstatements by men regarding prostate } \\
\text { cancer screening }\end{array}$ & $\begin{array}{l}\text { "And I walked in here basically thinking I knew } \\
\text { pretty much everything there was. But come } \\
\text { to find out, I skipped a test that I didn't know } \\
\text { about and I could be taking these } \\
\text { colonoscopies for years and still turn up with } \\
\text { prostate cancer." (FG4) } \\
\text { "I heard you, uh, have to take. . have to drink } \\
\text { something the night before. And then they } \\
\text { put you under and screen by going up in } \\
\text { there, right? Some kind of way. Get some } \\
\text { kind of sample or whatever." (FG2) }\end{array}$ \\
\hline
\end{tabular}

FG, focus group.

*Indicates code that was added during the iterative codebook review process.

without discussion of the benefits and risk. Clinicians also operated as barriers to men making informed decisions about screening if they did not address the topic (see lack of knowledge).

\section{Intrinsic Factors Impacting IDM}

\section{Pride}

Participants identified a notion of pride encompassing the importance of strength, virility, and not wanting to burden others. Pride was a barrier to IDM through causing men to avoid situations where PrCa screening is discussed. Participants often initially believed that the only way to screen for $\mathrm{PrCa}$ was with a digital rectal examination and felt that men would avoid talking about PrCa screening due to opposition to this examination.

Many men recognized pride as an important contributing factor to making an informed decision about PrCa screening (Table 2). Fear of losing sexual function as a downstream consequence of $\mathrm{PrCa}$ treatment was an especially important aspect of making a decision to be screened. A number of men also believed that the potential risk of urinary incontinence from $\mathrm{PrCa}$ treatment weighed heavily on the decision to be screened due to how it would impact pride. Several men additionally expressed the notion of not wanting to burden others with mental stress or be physically dependent on others if diagnosed with cancer.

\section{Care Avoidance}

Care avoidance, the failure of men to care for themselves or seek medical care even if they had the agency to do so, was noted by participants (Table 2). This factor was identified as a barrier to engaging in IDM about PrCa because men missed opportunities to discuss PrCa screening. Men commonly expressed that avoiding care was deeply engrained in culture and that historically men were raised in families where seeking care from doctors was not the norm. Participants also believed that most men would only seek care as a last resort if physical symptoms did not improve. As such, they would miss out on screening discussions that occur when men are healthy. Finally, men believed that Black men may avoid medical care because they are afraid of what might be discovered. 


\section{Motivated by Racial Disparities}

Being aware of racial PrCa disparities appeared to be a facilitating factor toward IDM about screening (Table 2). While some men came into the conversation with previous knowledge of $\mathrm{PrCa}$ disparities, many men became aware of these disparities during the presentation embedded within the focus group. Knowledge of disparities was a persuasive factor for a number of men to feel that undergoing $\mathrm{PrCa}$ screening was the obvious choice. In the absence of separate screening guidelines for Black men, some men felt that the presence of these disparities was sufficiently persuasive for Black men to want to be screened. Men also expressed a personal responsibility to share knowledge about $\mathrm{PrCa}$ screening with men in their community in light of this health disparity.

\section{Beliefs Impacting IDM}

Inadequate Care from the Medical Community Participants expressed a belief that the care provided to Black men was at times insufficient or substandard (Table 3). Patients perceived this inadequate care to stem from malfeasant motives from clinicians or from substandard care due to insurance status. The theme of distrust of the medical community was expressed by several different participants and was based on knowledge of the history of racist practices within the health care system. This distrust manifested through participants feeling that Black people may avoid care completely or not be totally open with clinicians about questions or concerns such as PrCa screening because information may be used against them, which served as a barrier to IDM.

A number of participants also shared a belief that the quality of care that they received was directly related to the quality of their insurance. These individuals were deterred from wanting to be screened for PrCa because they felt that their potential treatment options would be substandard based on their type of insurance.

In addition, men expressed distrust due to their awareness of racial disparities in $\mathrm{PrCa}$ outcomes, contrasted with the lack of discussion about these disparities with their clinicians. Some participants conveyed anger that clinicians accepted these disparities as facts of life rather than something to. make them outraged. These participants expressed that clinicians should be leading the charge to improve care by educating Black patients about PrCa screening to decrease racial disparities.

\section{Perceived Barriers}

Participants identified a number of perceived barriers to completing $\mathrm{PrCa}$ screening that were important to consider for their IDM (Table 3). Barriers included lack of access to screening and perceived harms from PrCa screening. Lack of access encompassed both lack of awareness that PrCa screening was available and monetary barriers such as insurance status and cost.

Perceived harms from PrCa screening included fear of the screening procedure, fear of a cancer diagnosis, fear of complications from prostate biopsy, fear of downstream side effects from PrCa treatment, and fear of being a burden if diagnosed with PrCa. These perceived harms promoted IDM about not wanting to be screened for PrCa. Fear of the screening procedure was generally related to aversion to a digital rectal prostate examination (see pride). Fear of cancer diagnosis was tied to a notion of fatalism that prevented men from wanting to be screened. Participants were significantly impacted by the potential risks of erectile dysfunction and urinary incontinence as downstream treatment consequences from PrCa screening.

\section{Perceived Risk and Perceived Severity}

Perceived risk of $\mathrm{PrCa}$ was an important facilitator for wanting to be screened or to find out more information to make an informed decision about screening. Risk perception was driven by 2 primary factors: physical symptoms and family history (Table 3). Many men correlated their personal risk with the presence or absence of urinary symptoms. These men expressed the feeling that their risk of $\mathrm{PrCa}$ was low, and they likely would not pursue screening if they felt well. Family history also played a large role in risk perception. Men's perceived risk was increased if they witnessed family members who dealt with any cancer, especially with PrCa. Conversely, men perceived themselves to be at low risk for $\mathrm{PrCa}$ if they did not have family members who had been diagnosed. Those with a family history were more motivated to seek out screening.

Perceived severity was a crucial component of men's IDM. Men described the seriousness of contracting PrCa and generally felt (incorrectly) that the diagnosis of $\mathrm{PrCa}$ was terminal. This 
perception of PrCa influenced men to want to be screened for $\mathrm{PrCa}$.

\section{Perceived Benefits}

Nearly all the participants believed that the main benefit from PrCa screening is that detecting cancer early could save lives (Table 3 ). This information was a powerfully motivating factor to want screening. Several participants also noted the benefit of relief that would come from a normal screening test. Other participants felt that getting as much information about their health and bodies was empowering, no matter what the result was.

\section{Identified Target Areas for Facilitation of IDM Lack of Knowledge}

Most participants felt that Black men lacked adequate knowledge to make informed decisions about PrCa (Table 4). Black men expressed a need to be better educated on the potential benefits and risks of PrCa screening before being asked to make a decision. This was a common thread that lack of education and communication from clinicians about PrCa screening was a large barrier to IDM.

Men trusted that if their clinician did not bring up PrCa screening that it must not be important. It was shocking for men to learn about the PrCa mortality statistics for Black men and realize that their clinicians had not addressed PrCa screening with them.

\section{Key Take-aways from Education Session}

Several concepts emerged as important takeaways from the facilitator-led education session. Participants were generally surprised to learn that guidelines frame PrCa screening as a personal choice rather than a universal recommendation (Table 4). Men also realized that the PSA blood test has limitations and does not determine if you have cancer or not. A number of men were previously unaware of the potential harms of screening and treatment of PrCa, notably erectile dysfunction and urinary incontinence after treatment. In turn, numerous participants were shocked and intimidated after learning about prostate biopsy and the risk of infection.

Once men processed that screening was a choice, most of the participants recognized that every man could express a personal decisional balance between perceived benefits of screening like avoiding death and the possible harms from screening or treatment like erectile dysfunction. One of the key takeaways was that men needed to consider their values when making a PrCa decision. Finally, participants expressed frustration at the limitation of medical knowledge, especially regarding $\mathrm{PrCa}$, specifically in Black men.

\section{Areas of Confusion}

There were several areas of confusion, defined as misstatements about PrCa screening, that were common across multiple focus groups (Table 4). These areas of confusion were barriers to making a truly informed decision about PrCa screening. A huge area of misunderstanding was that men frequently confused colon cancer screening with PrCa screening or believed that a colonoscopy tested for PrCa as well. Another common belief was that the only way to screen for PrCa was through a digital rectal examination. Many men were not aware that PrCa screening could be completed just with a PSA blood test. This point was an important misconception because aversion to the digital rectal examination played an important role in the decision to be screened. Finally, numerous men incorrectly attributed potential side effects from $\mathrm{PrCa}$ treatment to the physical procedure of being screened for PrCa. Most notably, men perceived that $\mathrm{PrCa}$ screening could directly cause erectile dysfunction, which was a strong deterrent to being screened.

\section{Discussion}

This study is the first to our knowledge that provided Black men with education about the benefits and risks of PrCa screening and evaluated how they processed this information applying key domains of IDM. We found that men felt ill-equipped to make a decision about PrCa screening. Lack of PrCa knowledge among Black men has been noted previously, ${ }^{30-33}$ but is especially important now that guideline societies recommend IDM. ${ }^{5,34,35}$ Participants in this study were shocked to learn that PrCa screening is a personal choice, which is consistent with previous work. ${ }^{8}$ Our study shed light on other important misconceptions about PrCa screening, such as confusion with colonoscopy and that a digital rectal examination is required for screening. These findings are important areas of future education for Black men. Studies indicate that physician-led discussions increase PrCa knowledge among Black men ${ }^{9,36,37}$ but that physicians are not routinely discussing $\mathrm{PrCa}$ screening with Black men. ${ }^{38,39}$ Whereas previous studies have recognized the important role clinicians can play in facilitating PrCa decision making, 
this study simultaneously acknowledges that clinicians can operate as barriers to IDM by not addressing $\mathrm{PrCa}$ screening or inadequately educating patients. This barrier threatens to increase mistrust in the medical community that already hinders the care provided to Black men. ${ }^{40,41} \mathrm{We}$ found that men were highly motivated by racial disparities in $\mathrm{PrCa}$, as well as the lack of adequate study of $\mathrm{PrCa}$ screening in Black men, to engage further in their own health as well as share knowledge with other Black men. Clinicians should inform Black men of PrCa disparities to facilitate both IDM and trust.

We found that sexuality, pride, partners, friends, family, and distrust of the medical community are all key aspects in the decisional balance of PrCa screening, as cited in previous work..$^{28,29,38}$ Our findings suggest that interventions to improve IDM would ideally tap these decisional balance domains and include both clinical and nonclinical components, with clinicians playing a central role. Simultaneously, the impact of important referent individuals and overcoming medical distrust are likely better addressed through community interventions. The participants in this study expressed a strong desire for more education and to share information learned with community peers. Past interventions with Black men have demonstrated that peer education is a successful strategy in PrCa screening ${ }^{39}$ and IDM. ${ }^{42}$ Our findings suggest that educating men about racial disparities may be a useful recruitment strategy for further peer education intervention work.

This study has several limitations. Participants were recruited through a convenience sample from 1 academic medical clinic that serves a predominately insured population, limiting its generalizability to other Black men. However, the consistency of our findings with previous literature strengthens the validity of our findings. Second, the moderator was a physician who had treated some of the participants as patients, resulting in response bias. We attempted to minimize this bias by asking about how other Black men would feel about the topics, in addition to how the men personally felt. Despite these limitations, this study adds to the current literature by expanding what is known about $\mathrm{PrCa}$ screening decision-making among Black men through a theory-based framework. Further work is needed to quantify what aspects of the PrCa screening decision are most influential to Black men and what men feel is adequate knowledge to make an informed decision. In addition, future investigations should evaluate the best manner to educate physicians on discussing IDM with Black patients and the impact of physician interventions on patient satisfaction with $\mathrm{PrCa}$ decision-making.

We would like to express our appreciation to Dr. Vanessa Diaz, MD MSCR, Ms. Carole Berini, Dr. William Moran, MD MS, and William Basco, MD MS, for their support of this research.

To see this article online, please go to: http://jabfm.org/content/ 34/5/925.full.

\section{References}

1. American Cancer Society. Cancer Statistics Center 2020: Prostate. Available from: https://cancerstatistics center.cancer.org/?_ga=2.35330471.761582147. 1603305079-1987363365.1603305079\#!/cancersite/Prostate. Accessed October 29, 2020.

2. Office of Disease Prevention and Health Promotion. Healthy People 2030: Reduce the prostate cancer death rate - C-08. Available from: https://health. gov/healthypeople/objectives-and-data/browseobjectives/cancer/reduce-prostate-cancer-death-rate-c08. Accessed June 1, 2021.

3. Schröder FH, Hugosson J, Roobol MJ, et al. ERSPC Investigators. Screening and prostate cancer mortality: results of the European Randomised Study of Screening for Prostate Cancer (ERSPC) at 13 years of follow-up. Lancet 2014;384:2027-35.

4. Pinsky PF, Prorok PC, Yu K, et al. Extended mortality results for prostate cancer screening in the PLCO trial with median follow-up of 15 years. Cancer 2017;123:592-9.

5. US Preventive Services Task Force. Screening for prostate cancer: US Preventive Services Task Force Recommendation Statement. JAMA 2018;319:1901-13.

6. Centers for Disease Control and Prevention, National Center for Health Statistics. National Health Interview Survey, 2017. Available from: https://progressreport.cancer.gov/detection/prostate_ cancer. Accessed June 1, 2021.

7. Shi L, Lebrun LA, Tsai J. Access to medical care, dental care, and prescription drugs: the roles of race/ethnicity, health insurance, and income. South Med J 2010;103:509-16.

8. Leyva B, Persoskie A, Ottenbacher A, et al. Do men receive information required for shared decision making about PSA Testing? Results from a national survey. J Cancer Educ 2016;31:693-701.

9. Woods-Burnham L, Stiel L, Wilson C, et al. Physician consultations, prostate cancer knowledge, and PSA screening of African American men in the era of shared decision-making. Am J Mens Health 2018;12:751-9.

10. Forrester-Anderson IT. Prostate cancer screening perceptions, knowledge and behaviors among 
African American men: focus group findings. J Health Care Poor Underserved 2005; 16:22-30.

11. Reynolds D. Prostate cancer screening in African American men: barriers and methods for improvement. Am J Mens Health 2008;2:172-7.

12. Gelfand D, Parzuchowski J, Cort M, Powell I. Digital rectal examinations and prostate cancer screening: attitudes of African American men. Oncol Nurs Forum 1995;22:1253-5.

13. Machirori M, Patch C, Metcalfe KN. Study of the relationship between Black men, culture and prostate cancer beliefs. Cogent Medicine 2018;5:1442636-13.

14. Kleier J. Prostate cancer in black men of African Caribbean descent. J Cult Divers 2003;10:56-61.

15. Luque JS, Rivers BM, Gwede CK, Kambon M, Green BL, Meade CD. Barbershop communications on prostate cancer screening using barber health advisers. Am J Mens Health 2011;5:129-39.

16. Wray RJ, Vijaykumar S, Jupka K, Zellin S, Shahid M. Addressing the challenge of informed decision making in prostate cancer community outreach to African American men. Am J Mens Health 2011;5:508-16.

17. Holt CL, Le D, Saunders DR, et al. Informed decision-making and satisfaction with a church-based men's health workshop series for African-American men: men-only vs. mixed-gender format. J Cancer Educ 2015;30:530-4.

18. Roberts LR, Wilson CM, Stiel L, Casiano CA, Montgomery SB. Prostate cancer screening among high-risk Black men. J Nurse Pract 2018;14:677-82.e2.

19. Briss P, Rimer B, Reilley B, et al. Task Force on Community Preventive Services. Promoting informed decisions about cancer screening in communities and healthcare systems. Am J Prev Med. 2004;26:67-80.

20. Prochaska JO, DiClemente CC. Stages and processes of self-change of smoking: Toward an integrative model of change. J Consult Clin Psychol 1983;51:390-5.

21. Tong A, Sainsbury P, Craig J. Consolidated criteria for reporting qualitative research (COREQ): a 32item checklist for interviews and focus groups. Int J Qual Health Care 2007;19:349-57.

22. Kruger RA. Developing Questions for Focus Groups. Sage; 1998.

23. American Cancer Society. Cancer Facts \& Figures for African Americans 2016-2018. 2016. Available from: https://www.cancer.org/research/cancer-factsstatistics/cancer-facts-figures-for-african-americans. html. Accessed June 2, 2021.

24. Strauss A, Corbin J. Basics of qualitative research: Grounded theory procedures and techniques. Sage; 1990.

25. Muliira JK, Al-Saidi HS, Al-Yahyai AN. Determinants of behavioral intentions to screen for prostate cancer in Omani men. Asia Pac J Oncol Nurs 2017;4:348-55.
26. NVivo qualitative data analysis software [Computer software]. Version 12:ed.: QSR International Pty Ltd 2018;

27. Crabtree BF, Miller W. A template approach to text analysis: Developing and using codebooks. In: Crabtree BF, Miller W, eds. Doing qualitative research. Sage Publications; 1992: 93-109.

28. Allen JD, Kennedy M, Wilson-Glover A, Gilligan TD. African-American men's perceptions about prostate cancer: implications for designing educational interventions. Soc Sci Med 2007;64:2189200.

29. Sanchez MA, Bowen DJ, Hart Jr, Spigner AC. Factors influencing prostate cancer screening decisions among African American men. Ethn Dis 2007;17:374-80.

30. Barber KR, Shaw R, Folts M, et al. Differences between African, American, and Caucasian men participating in a community-based prostate cancer screening program. J Comm Health 1998;23: 441-51.

31. Shavers VL, Underwood W, Moser RP. Race/ethnicity and the perception of the risk of developing prostate cancer. Am J Prev Med 2009;37:64-7.

32. Woods VD, Montgomery SB, Belliard JC, Ramirez-Johnson J, Wilson CM. Culture, black men, and prostate cancer: what is reality? Cancer Control 2004;11:388-96.

33. Jones RA, Steeves R, Williams I. How African American men decide whether or not to get prostate cancer screening. Cancer Nurs 2009;32: 166-72.

34. Wolf AM, Wender RC, Etzioni RB, et al. American Cancer Society guideline for the early detection of prostate cancer: update 2010. CA Cancer J Clin. American Cancer Society Prostate Cancer Advisory Committee2010;60:70-98.

35. Carter HB, Albertsen PC, Barry MJ, et al. Early detection of prostate cancer: AUA guideline. J Urol 2013;190:419-26.

36. Ross L, Dark T, Orom H, et al. Patterns of information behavior and prostate cancer knowledge among African-American men. J Cancer Educ 2011;26:708-16.

37. Roussi P, Miller SM, Giri VN, et al. Effects of a randomized trial comparing standard and enhanced counseling for men at high risk of prostate cancer as a function of race and monitoring style. J Health Psychol 2018;23:1800-9.

38. Davis SN, Diefenbach MA, Valdimarsdottir H, Chen T, Hall SJ, Thompson HS. Pros and cons of prostate cancer screening: associations with screening knowledge and attitudes among urban African American men. J Natl Med Assoc 2010;102:174-82.

39. Weinrich SP, Boyd MD, Weinrich M, Greene F, Reynolds WA, Jr, Metlin C. Increasing prostate 
cancer screening in African American men with peer-educator and client-navigator interventions. J Cancer Educ 1998;13:213-9.

40. LaVeist TA, Nickerson KJ, Bowie JV. Attitudes about racism, medical mistrust, and satisfaction with care among African American and white cardiac patients. Med Care Res Rev 2000;57 Suppl $1: 146-61$.
41. Carpenter WR, Godley PA, Clark JA, et al. Racial differences in trust and regular source of patient care and the implications for prostate cancer screening use. Cancer 2009;115:5048-59.

42. Robinson M, Sartor A, Jack L. Educating African American men on prostate health and informed decision making: initial report from a peer-education program in Louisiana. JCO 2011;29:211. 
Appendix 1: Evolution of Codebook to Define Barriers And Facilitators to Prostate Cancer Screening Informed Decision-Making

Step I. Initial Codebook Development Phase

A. Initial codebook development was guided by the US Community Preventive Services Taskforce Informed Decision-Making Framework, ${ }^{19}$ which includes domains: (1) understands the test, the condition, personal risks, uncertainties, (2) considers preferences, (3) participates participates in decision at a personally desirable level, (4) and makes a decision consistent with values. Review of the literature resulted in the addition of 2 more codes (clinician communication, inadequate care from medical community). Review of the codebook by 2 coinvestigators lead to refinement of definitions to reflect perceptions of test related complications in addition to perceptions of prostate cancer itself, removal/consolidation of several codes (attitude about the test, utilities/values, treatment preference, role preference, test preference, intention to screen, screening, and satisfaction with decision).

B. Review of modified codebook by 2 coinvestigators with addition of 2 codes to capture key take-aways from education session and areas of confusion.

\section{Step II. Codebook Testing Phase}

A. Focus group 1 coded by 2 independent coders with code refinement including the following changes:

- Updated perceived risk definition to include the idea of thinking that something is wrong

- Revised clinician communication definition to "Impact of clinician on a man's behavior or understanding." Removed role preference node as this is captured in clinician communication node

- Included a descriptive note in the "knowledge" section that it includes men's conclusions based on past experiences

- Created new "interpersonal influence" node defined as "Impact of important referent individuals on an individual's opinions or beliefs about his health. Includes both direct communication and hearing stories of what has happened to friends/family."

- Decisional conflict node removed as it was very similar to decisional balance node.

- Created new "doctor avoidance" node defined as "avoiding seeing a doctor even if 1 has the agency to do so

- Created new "pride" node defined as "a feeling of manhood encompassing the importance of strength, virility, and not wanting to burden others." Got rid of "fear of being a burden" node

- Created new "motivated by disparities" node defined as "Black men are motivated to seek additional health information or to change health behaviors due to their knowledge of health disparities."

B. Additional codebook changes after review of focus group 1

- Created new "information sharing" node defined as "The desire to share information about prostate cancer and prostate cancer screening with members of the community. In addition includes what advice men would tell other men about prostate cancer screening."

- Deleted "normative beliefs" node and incorporated this within the "interpersonal influences" node

- Deleted "self-efficacy node" and incorporated this into "decisional balance."

- Expanded definition of "perceived benefits" to "A man's perception of the positive outcomes derived from completing prostate cancer screening."

\section{Step III. Active Coding Phase}

A. Focus group 2 reviewed by 2 independent coders with following updates:

- Codebook note added that trusted sources providing information through media are encompassed in "interpersonal influences."

B. Focus group 3 reviewed by 2 independent coders with following updates:

- Broadened definition of "Doctor Avoidance" to "Care Avoidance" defined as "Failure to care for oneself or seek medical care even if 1 has the agency to do so."

- Broadened definition of "distrust of medical community" to "inadequate care from medical community" defined as "Men believe that the care provided to them is insufficient or substandard, or men believe that the information provided to them by the medical community is incorrect or not applicable to their personal situation."

- Created new theme called "lack of knowledge" defined as "A man not possessing sufficient information about prostate cancer screening to make an informed decision." This was a subtheme within the "clinician communication" code that focuses on information that was not provided by the clinician.

- Removed "knowledge" theme as "lack of knowledge" was a more important factor

- Removed "decisional balance" theme as this was covered in "perceived benefits" and "perceived barriers."

C. Final codebook applied to remaining focus groups 